\title{
Novel laccase-like multicopper oxidases from the Myrothecium roridum fungus - production enhancement, identification and application in the dye removal process
}

\author{
Anna Jasińska ${ }^{凶}$, Aleksandra Góralczyk, Adrian Soboń and Jerzy Długoński \\ Department of Industrial Microbiology and Biotechnology, Faculty of Biology and Environmental Protection, University of Lodz, Łódź, Poland
}

\begin{abstract}
The aim of this study was to overproduce, identify and apply novel laccase-like multicopper oxidases (LMCOs) from Myrothecium roridum in a dye removal process. LMCOs' production was enhanced by modifying the medium and adding copper ions. After purification, two proteins, LMCO1 and LMCO2, with molecular masses of 46.7 and $66.3 \mathrm{kDa}$ were discovered. Peptide analysis by mass spectrometry revealed that they belong to the cupredoxin superfamily. Characteristic peptide sequences were obtained for MCOs and bilirubin oxidases. Crude enzymes were applied in a dye decolorization process. Supplementation with $1 \mathrm{mM}$ of vanillin allowed an almost complete elimination of the Indigo carmine within 3 hours. The dye was removed from a solution containing metals, surfactants and organic solvents. The in-gel assessment of the activity and decolorization ability of MCOs, followed by protein extraction and SDS-PAGE, confirmed that only LMCO2 was responsible for the dye removal. MCOs produced by Myrothecium sp. have been poorly studied before. The obtained results broaden knowledge on this subject and may contribute to the development of an eco-friendly method of dye elimination.
\end{abstract}

Key words: multicopper oxidases, laccase, bilirubin oxidase, Myrothecium roridum, decolorization

Received: 19 December, 2017; revised: 13 March, 2018; accepted: 19 March 2018; available on-line: 25 April, 2018

e-mail: anna.jasinska@biol.uni.lodz.pl

Abbreviations: MCOs, multicopper oxidase; LMCOs, laccase-like multicopper oxidases; ABTS, 2,2-azinobis-3-ethylbenzothiazolin6-sulfonic acid; DMP, 2,6-dimethoxyphenol; TEMPO, 2,2,6,6-tetramethylpiperidine 1-oxyl

\section{INTRODUCTION}

Multicopper oxidases (MCOs) belong to a family of proteins that catalyse a one-electron oxidation of substrate while simultaneously reducing molecular oxygen to water (Hoegger et al., 2006). Laccases constitute the largest and probably the most researched subgroup within MCOs that oxidize a broad range of organic substrates (including phenols, polyphenols, and anilines) and even certain inorganic compounds. Therefore, MCOs are an excellent tool for the biodegradation process of toxic pollutants, e.g. synthetic dyes (Desai \& Nityanand, 2011; Jasińska et al., 2016).

Approximately $2.8 \times 10^{5}$ tons of dyes that are produced each year are lost in the effluents and can lead to water eutrophication and disruption of the circulation of biogenic elements, and adversely affect organisms at all levels of the trophic chain Jasińska et al., 2016; Paz et al.,
2017). The most frequently used physical and chemical methods of dye elimination are associated with environmental and economic limitations. An alternative solution is to use biological methods. Therefore, there is a need for a good strategy of searching for new microorganisms producing these enzymes and increasing the productivity of biocatalysts. Given the difficulties in expressing these enzymes heterologously, optimization of the fermentation medium and application of inducers are used to achieve the MCOs overproduction. The most crucial parameters are sugar and nitrogen sources, their concentration, $\mathrm{C} / \mathrm{N}$ ratio and supplementation with inducers, e.g. copper or xylidine. These parameters are species-specific and thus cannot be extrapolated to other species (Gupta et al., 2015). The high cost associated with enzyme purification is a drawback of this technology. However, the use of a crude enzyme would greatly reduce the cost of operation. In many cases, crude enzymes are more stable in various environmental conditions because of the protective role of other companion molecules (Levin et al., 2008).

In this study, we propose a method to enhance the laccase-like MCOs (LMCOs) production using an ascomycetous strain of Myrothecium roridum, whose biocatalytic potential we had previously described (Jasińska et al., 2012; Jasińska et al., 2013; Jasińska et al., 2015). The enzymes were purified, identified with the use of mass spectrometry, and applied in elimination of dyes belonging to different chemical groups. The influence of inorganic ions and organic compounds, frequently present in the dye-loaded wastewater, on the decolorization activity of the enzymes was also established. An in-gel decolorizing potential screening with the use of Native-PAGE, protein extraction and molecular weight determination via SDS-PAGE was used to confirm one of the LMCOs as the major decolorizer of dyes.

\section{MATERIALS AND METHODS}

Chemicals and the fungal strain. 2,2-azinobis-3-ethylbenzothiazolin-6-sulfonic acid (ABTS), 2,6-dimethoxyphenol (DMP), 2,2,6,6-tetramethylpiperidine 1-oxyl (TEMPO), 4-hydroxybenzoic acid, caffeic acid, catechol, vanillin, bilirubin and guaiacol were purchased from SigmaAldrich (USA). The dyes used in the induction and decolorization studies were purchased from Sigma-Aldrich or kindly supplied by Boruta-Zachem Kolor Co. (Poland). Remaining chemicals were from Promega (USA), Serva (Germany), Bio-Rad (USA) and POCh (Gliwice, Poland). Filamentous fungus $M$. roridum IM 6482 was isolated on ZT plates from soil samples collected around a textile dyeing factory. The strain was identified by molecular techniques (Jasińska et al., 2012) and preserved on 
ZT slants at $4^{\circ} \mathrm{C}$ in the strain collection of the Department of Industrial Microbiology and Biotechnology, University of Lodz (Poland).

LMCOs production enhancement. $M$. roridum IM 6482 was cultivated at $28^{\circ} \mathrm{C}$ in $100 \mathrm{ml}$ Erlenmeyer flasks containing $18 \mathrm{ml}$ of liquid medium inoculated with 2 $\mathrm{ml}$ of a homogenous second-step preculture ( $24 \mathrm{~h}$-old) prepared in a liquid WHI medium. Cultivation parameters were optimized with a conventional "one-factorat-a-time" methodology to obtain maximum laccase-like enzymes' production. The medium used for the enzyme production contained (in $\mathrm{g} / \mathrm{L}$ ) $\mathrm{K}_{2} \mathrm{HPO}_{4}-1.00, \mathrm{MgSO}_{4}$ $-0.50, \mathrm{KCl}-0.50$ and $\mathrm{FeSO}_{4}-0.01$, as well as one of the above-mentioned carbon and nitrogen sources To determine the influence of the carbon source and concentration, a medium containing $7.50,15.00$ or 30.00 $\mathrm{g} / \mathrm{L}$ of glucose or sucrose was used. Further experiments were performed with the use of a medium with $0.75 \%$ sucrose, along with sodium nitrate or yeast extract $(0.50$ or $3.00 \mathrm{~g} / \mathrm{L})$. An optimized medium was used for the study of the inducers' impact on laccase-like enzyme production. Heavy metals, aromatic compounds and dyes were suspended in deionized water and sterilized by filtration before use. At appropriate time intervals, the cultures were centrifuged at $3500 \times g$ for $15 \mathrm{~min}$, and laccase activity, expressed as ABTS oxidation, was determined spectrophotometrically according to the method described earlier by Eggert et al. (1996), with slight modifications.

Proteins precipitation, purification and identification by mass spectrometry. Crude fungal culture was centrifuged, and the obtained filtrate was used for the protein precipitation. Solid ammonium sulfate was slowly added to the crude extract to give $80 \%$ saturation, and the solution was stirred gently for at least 1 hour at $4^{\circ} \mathrm{C}$ and then left to stand overnight. The precipitate was collected and dissolved in a $50 \mathrm{mM}$ potassium phosphate buffer ( $\mathrm{pH}$ 7.2). The protein solution was desalted and concentrated by ultrafiltration with $10 \mathrm{kDa}$ cutoff (Ultra-15, Amicon, Bedford, MA, USA). Protein concentration was determined using the BCA method (according to the Pierce ${ }^{\mathrm{TM}}$ BCA Protein Assay Kit protocol).

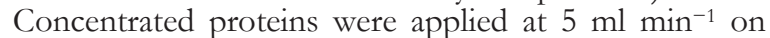
a HiTrap DEAE column (5 mL) pre-equilibrated with $50 \mathrm{mM}$ potassium phosphate buffer ( $\mathrm{pH} 7.2)$. Adsorbed proteins were sequentially eluted with $0.1,0.25,0.5,0.75$, and $1 \mathrm{M} \mathrm{NaCl}$ in a potassium phosphate buffer. The laccase activity and the total protein content of all fractions were determined. The fractions with laccase activity were pooled, concentrated by ultrafiltration with $10 \mathrm{kDa}$ cutoff (Ultra-0.5, Amicon, Bedford, MA, USA) and stored at $4^{\circ} \mathrm{C}$ for further use. For molecular mass determination, a standard SDS-PAGE procedure was used (Soboń et al., 2016). The gel was calibrated with the molecular mass marker in the range of 6500-200000 Da (SigmaAldrich, Germany) and stained with Coomassie blue.

Protein digestion was performed according to the procedure described by Szewczyk and coworkers (2015). Selected protein bands were cut, undyed and the proteins were reduced and acylated. Then, the proteins were digested overnight at $37^{\circ} \mathrm{C}$ using trypsin (Promega, USA). The obtained peptides were extracted twice using $30 \mu \mathrm{L}$ of $0.1 \%$ trifluoroacetic acid solution in $2 \%$ acetonitrile on a rotary shaker, evaporated to dryness and stored at $4^{\circ} \mathrm{C}$. Before analysis, the dry extract was resuspended in $10 \mu \mathrm{L}$ of a peptide extraction solution. An AB Sciex $5800 \mathrm{TOF} / \mathrm{TOF}$ instrument (AB Sciex, USA) was used for data acquisition. The samples were placed on the MALDI plate three times to cover selection of the 15 strongest precursors for an MS/MS analysis. All of the instrument parameters used for analysis were described by Szewczyk and coworkers (2015). The Protein Pilot v4.0 software (AB Sciex), coupled with the MASCOT search engine $\mathrm{v} 2.3$, was used for database searches. The data were searched against the NCBI database using a few filtering sets: fungi (8156643 sequences), fungal laccases (5985 sequences) and fungal oxidases (92935 sequences). The identified and unidentified proteins were further processed using a BLAST search against the NCBI non-redundant protein sequences (83141305), using the DELTA-BLAST algorithm.

Decolorization studies. Decolorization experiments were performed in 96-well plates using a reaction mixture containing $50 \mathrm{mM}$ potassium phosphate buffer ( $\mathrm{pH} 7.2$ ), crude enzymes with laccase activity toward ABTS at 1 $\mathrm{U} / \mathrm{mL}$, various concentrations of the dye $(10-200 \mathrm{mg} / \mathrm{L})$ and vanillin $(25-1000 \mu \mathrm{M})$. A decrease in the maximum absorbance of the dye was monitored to determine its elimination. Decolorization percentage (DP) was calculated according to the formula: $\mathrm{DP}[\%]=\left[100 \times\left(\mathrm{A}_{0}-\mathrm{A}_{\mathrm{t}} /\right.\right.$ $\left.A_{0}\right)$ ], where $A_{0}$ and $A_{t}$ are the initial absorbance of the reaction mixture and the absorbance after incubation time, respectively.

Dye decolorizing enzyme identification. Non-denaturing (Native-PAGE) electrophoresis was performed on a $10 \%$ mini gel prepared according to the procedure described in the manufacturer's instructions (Mini-PROTEAN Tetra Cell; Bio-Rad, USA). The samples (containing $10 \mu \mathrm{g}$ of proteins) were mixed with a Laemmli Sample Native Buffer (Bio-Rad, USA) at the ratio of 1:1 $(\mathrm{v} / \mathrm{v})$, and loaded on the gel without thermal denaturation. Electrophoresis was conducted at $150 \mathrm{~V}$ until the dye front reached the bottom level. The gel was cut and stained with ABTS $(2.5 \mathrm{mM})$, bilirubin $(10 \mu \mathrm{M})$ or Indigo Carmine (50 $\mathrm{mg} / \mathrm{L}$, with $1 \mathrm{mM}$ vanillin) solution. When decolorized bands appeared, they were cut out and overnight protein extraction with phosphate buffer $(\mathrm{pH}$ 7.2) was conducted. The obtained proteins were concentrated using Amicon Ultra $0.5 \mathrm{~mL}$ filters (Merck Millipore) and a standard SDS-PAGE procedure was used for molecular mass determination.

Statistical analysis. Experiments were performed in triplicate. A one-way variance analysis was used to determine the significance of the differences between the samples. All of the statistical analyses were performed using Excel 2007 (Microsoft Corporation, USA). The readings were considered to be significant when $p$ was $\leq 0.05$.

\section{RESULTS}

\section{Enhancement of LMCOs production}

The carbon (glucose or sucrose) and nitrogen (sodium nitrate or yeast extract) sources, as well as inducer supplementation were tested to improve the laccase-like enzyme production. At appropriate time intervals for each experiment, the laccase activity was measured with the use of ABTS as a substrate. The fungus produced the LMCOs enzymes on both carbon sources (Fig. 1); however, glucose yielded the highest laccase-like enzyme production within 144 hours of cultivation (which corresponded to the end of the stationary phase of growth). Production of the enzyme reached its maximum level when $7.50 \mathrm{~g} / \mathrm{L}$ of glucose was used. At higher glucose concentrations, the enzyme production decreased. The effect of organic (yeast extract) and inorganic (sodium nitrate) nitrogen sources on LMCOs production by 


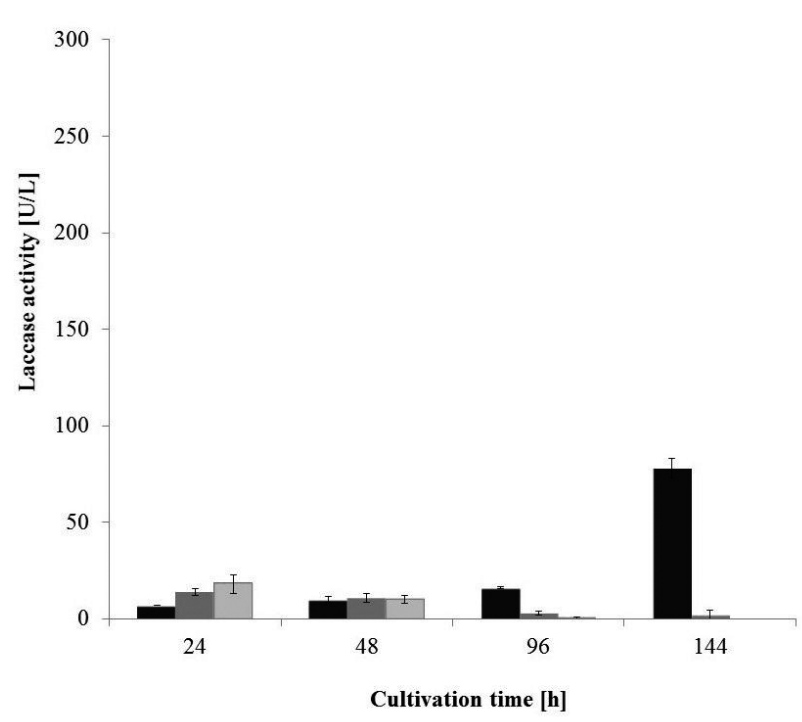

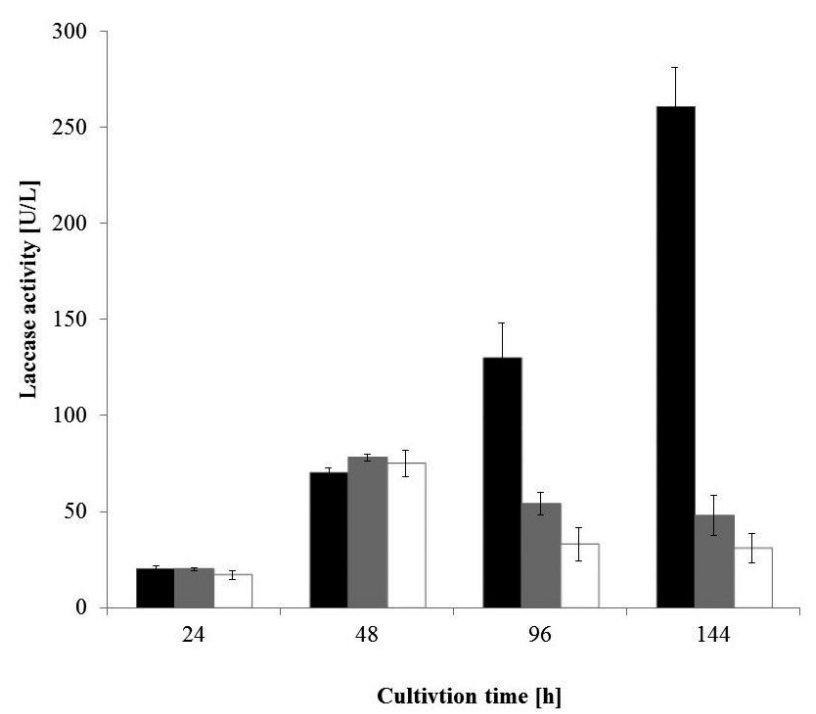

Figure 1. Effect of the carbon source on $M$. roridum laccase-like enzyme production in a medium containing 0.75 (black), 1.50 (grey) or 3.00 (white) \% of sucrose (A) or glucose (B).

M. roridum IM 6482 when grown with $7.50 \mathrm{~g} / \mathrm{L}$ glucose was assessed (Fig. 2). Optimal enzyme production (298 $\mathrm{U} / \mathrm{L})$ was achieved when using a yeast extract $(3.00 \mathrm{~g} / \mathrm{L})$ as the only $\mathrm{N}$-source. Although production was similar to that achieved in a medium containing $\mathrm{NaNO}_{3}$, the enzyme was synthesized faster, and the highest activity was achieved within 48 hours of cultivation. As presented in Table 1, addition of copper ions to the growth medium enhanced laccase production from $287.93 \mathrm{U} / \mathrm{L}$ to 2134.44 U/L. The other heavy metals tested decreased the enzyme secretion, probably by suppressing fungal growth. A screening of several exogenous aromatic compounds for their effect on $M$. roridum laccase induction indicated guaiacol $(20 \mathrm{mM})$ as the most significant inducer, which enhanced the enzyme production by up

A

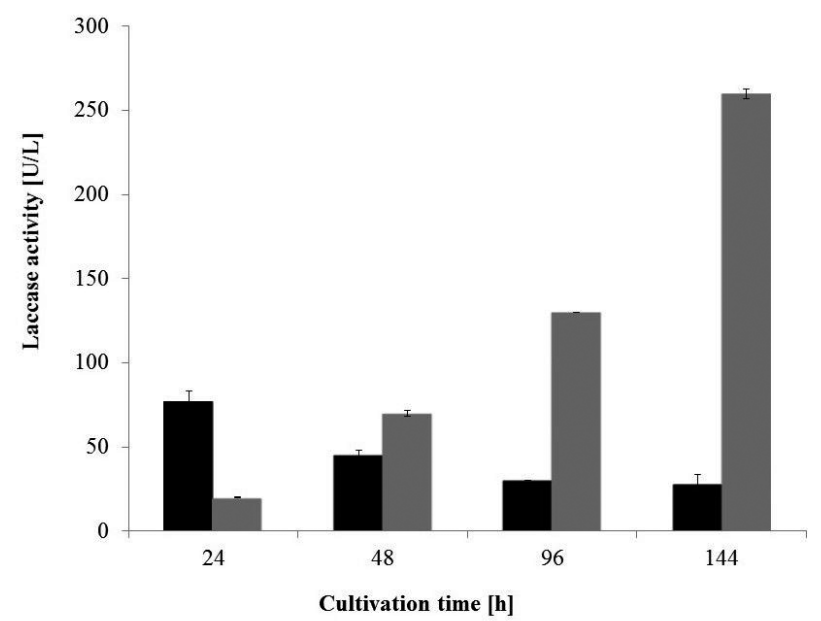

to two-folds. In the presence of dyes at the initial concentration of $10 \mathrm{mg} / \mathrm{L}$, suppression of laccases synthesis was observed.

\section{Laccase-like enzyme purification and identification}

LMCOs were purified from ammonium sulfate precipitated proteins. After ion-exchange chromatography, two fractions with laccase activity, annotated as LMCO1 and LMCO2, were obtained. The proteins had molecular masses of 46.7 and $66.3 \mathrm{kDa}$, respectively (Fig. 3). Each of them exhibited a single band on SDS-PAGE, suggesting a homogenous form. Specific activity of LMCO1 was 14.65, and of LMCO2 it was $128.58 \mathrm{U} \mathrm{mg}^{-1}$, when estimated with ABTS as the substrate (Table 2). To identify the obtained proteins, an in-gel digestion

B

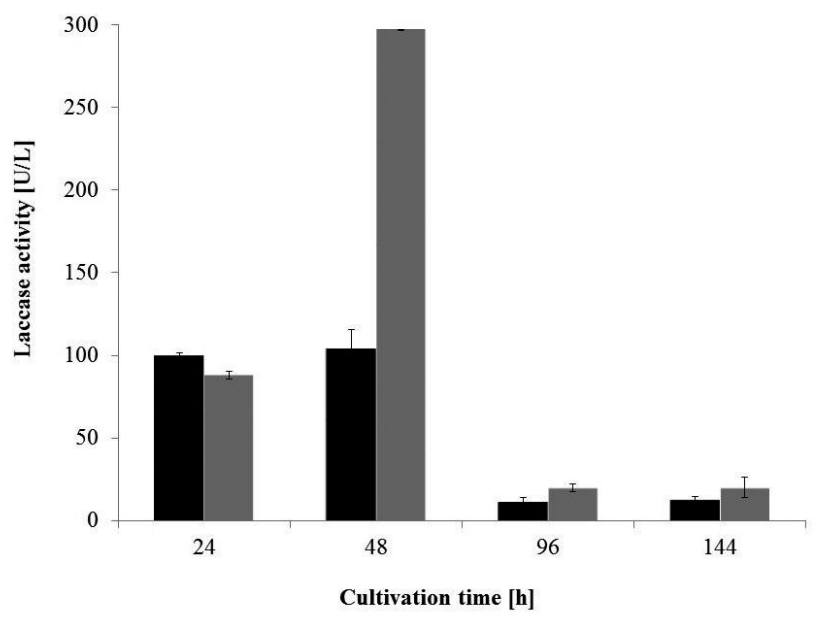

Figure 2. Effect of the nitrogen source on laccase-like enzyme production by M. roridum in a medium containing 0.05 (black) or 3.00 (grey) $\mathrm{g} / \mathrm{L}$ of (A) $\mathrm{NaNO}_{3}$ or (B) yeast extract. 
Table 1. Effect of chemical inducers on LMCOs production by M. roridum.

\begin{tabular}{|c|c|c|c|}
\hline Inducer & & $\begin{array}{l}\text { LMCOs activity } \\
{[U / L]}\end{array}$ & $\begin{array}{l}\text { Mycelial dry weight } \\
{[\mathrm{g} / \mathrm{L}]}\end{array}$ \\
\hline Without inducer & & $287.93 \pm 10.21$ & $3.65 \pm 0.39$ \\
\hline \multirow{5}{*}{$\begin{array}{l}\text { Heavy metal } \\
(1 \mathrm{mM})\end{array}$} & $\mathrm{Cu}^{2+}$ & $2134.44 \pm 26.09$ & $3.41 \pm 0.25$ \\
\hline & $\mathrm{Zn}^{2+}$ & $62.22 \pm 4.32$ & $1.52 \pm 0.02$ \\
\hline & $\mathrm{Mg}^{2+}$ & $97.64 \pm 3.73$ & $2.05 \pm 0.15$ \\
\hline & $\mathrm{Cd}^{2+}$ & NA & $2.35 \pm 0.35$ \\
\hline & $\mathrm{Mn}^{2+}$ & $71.94 \pm 10.82$ & $2.96 \pm 0.03$ \\
\hline \multirow{4}{*}{$\begin{array}{l}\text { Aromatic compound } \\
(100 \mu \mathrm{M})\end{array}$} & ABTS & $119.03 \pm 6.48$ & $3.52 \pm 0.15$ \\
\hline & DMP & $58.47 \pm 1.39$ & $3.38 \pm 0.25$ \\
\hline & Caffeic acid & $223.47 \pm 7.13$ & $2.43 \pm 0.11$ \\
\hline & Guaiacol & $540.00 \pm 18.46$ & $2.18 \pm 0.18$ \\
\hline \multirow{5}{*}{$\begin{array}{l}\text { Dye } \\
(10 \mathrm{mg} / \mathrm{L})\end{array}$} & Malachite green & $191.39 \pm 16.89$ & $2.3 \pm 0.03$ \\
\hline & Rhodamine B & $59.86 \pm 9.86$ & $2.00 \pm 0.07$ \\
\hline & Acid orange 7 & $54.31 \pm 2.95$ & $1.43 \pm 0.11$ \\
\hline & Direct black 22 & $131.61 \pm 21.61$ & $1.70 \pm 0.21$ \\
\hline & Methylene blue & $252.22 \pm 6.36$ & $1.90 \pm 0.14$ \\
\hline
\end{tabular}

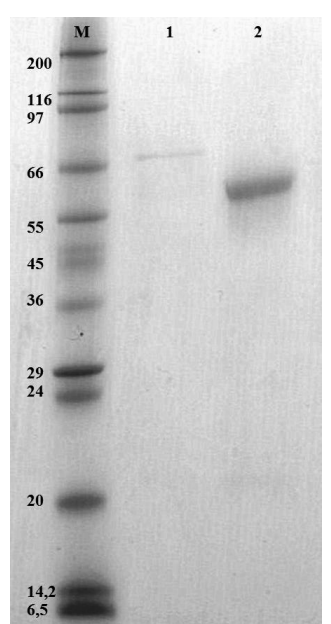

Figure 3. SDS-PAGE analysis of purified LMCO1 and LMCO2 of $M$. roridum. $M$, protein molecular mass marker; 1 , purified LMCO2; 2, purified LMCO1.

procedure, and a MALDI-TOF/TOF analysis were then performed. For both purified proteins, the characteristic peptide sequences (KGGEWTINGVTFADVENR, TLWYHDHAMHITAENAYR, FINNAEAPNSVHLHGSFSR, APFDGWAEDVTNPGEFK) were obtained for several enzymes, such as MCOs from Macrophomina phaseolina MS6, and bilirubin oxidase from Myrothecium verrucaria and Magnaporthe oryzae (Table 3). Delta-BLAST analysis showed that LMCO1, as well as LMCO2, belong to the cupredoxin superfamily. Histidine-rich amino acid sequences that are typical for MCOs were found. The mass spectra of the M. roridum LMOCs are presented in Supporting information (Supporting information Suplementary Fig. S1 at www.actabp.pl).

\section{Decolorization study}

Dye decolorization by crude $M$. roridum LMCOs

In this step of the study, the dye decolorizing ability of crude LMCOs from $M$. roridum fungus was screened toward four groups of dyes: indigoid, anthraquinone, azo and phthalocyanine, added at the concentrations of 10 or $50 \mathrm{mg} / \mathrm{L}$. Dyes tested in the study were decolorized to varying degrees. Surprisingly, the highest decolorization was obtained for Indigo carmine, which is not a typical phenol substrate of laccase. After 48 hours of incubation with the crude enzyme (with the activity toward ABTS at $1 \mathrm{U} / \mathrm{mL}$ ), decolorization of the dye at the concentrations of 10 and $50 \mathrm{mg} / \mathrm{L}$ reached 78.8 and $47.1 \%$, respectively (Fig. 4). Direct blue 86 and Acid orange 7, belonging to phthalocyanine and azo dyes, were also decolorized to an extent higher than $15 \%$ at both concentrations tested.

Table 2. Purification steps of LMCOs produced by M. roridum.

\begin{tabular}{llllc}
\hline Step & $\begin{array}{l}\text { Protein } \\
{[\mathrm{mg} / \mathrm{ml}]}\end{array}$ & $\begin{array}{l}\text { Activity } \\
{[\mathrm{U} / \mathrm{ml}]}\end{array}$ & $\begin{array}{l}\text { Specific activity } \\
{[\mathrm{U} / \mathrm{mg}]}\end{array}$ & Purification fold \\
\hline Crude enzymes & 1.553 & 3.545 & 2.282 & 1.0 \\
\hline Precipitate & 0.854 & 9.342 & 10.939 & 4.8 \\
\hline Purified LMCO1 & 0.058 & 0.850 & 14.655 & 6.4 \\
\hline Purified LMCO2 & 0.012 & 1.543 & 128.583 & 56.3 \\
\hline
\end{tabular}


Table 3. Amino acid sequences of: (A) LMCO1 and (B) LMCO2 peptides detected by peptidic footprint and peptide fragmentation.

\begin{tabular}{|c|c|c|c|c|}
\hline Sequence & Score & Protein name & Organism & Accession No \\
\hline DVVWLGR & 50 & bilirubin oxidase & Magnaporthe oryzae & gi|351650312 \\
\hline APFDGWAEDVTNPGEFK & 134 & & & \\
\hline DVVWLGR & 50 & bilirubin oxidase & Myrothecium verrucaria & gi|456710 \\
\hline TLWYHDHAMHITAENAYR & 91 & & & \\
\hline FINNAEAPNSVHLHGSFSR & 63 & & & \\
\hline \multirow[t]{2}{*}{ KGGEWTINGVTFADVENR } & 109 & multicopper oxidase type 1 & Macrophomina phaseolinaMS6 & gi|407927636 \\
\hline & 109 & putative bilirubin oxidase precursor & Diplodia seriata & gi|821060559 \\
\hline DVVWLGR & 50 & hypothetical protein SNOG_08624 & Parastagonospora nodorumSN15 & gi|160702204 \\
\hline DYYYPNNQAAR & 48 & & & \\
\hline DVVWLGR & 50 & hypothetical protein COCSADRAFT_354546 & Bipolaris sorokinianaND90Pr & gi|451852094 \\
\hline DYYYPNNQAAR & 48 & & & \\
\hline
\end{tabular}

\begin{tabular}{|c|c|c|c|c|}
\hline Sequence & Score & Protein name & Organism & Accession No \\
\hline APFDGWAEDVTNPGEFK & 110 & bilirubin oxidase & Magnaporthe oryzae & gi|351650312 \\
\hline TLWYHDHAMHITAENAYR & 33 & bilirubin oxidase & Myrothecium verrucaria & gi|456710 \\
\hline FINNAEAPNSVHLHGSFSR & 60 & & & \\
\hline \multirow[t]{2}{*}{ KGGEWTINGVTFADVENR } & 100 & multicopper oxidase type 1 & Macrophomina phaseolinaMS6 & gi|407927636 \\
\hline & 100 & putative bilirubin oxidase precursor & Diplodia seriata & gi|821060559 \\
\hline
\end{tabular}

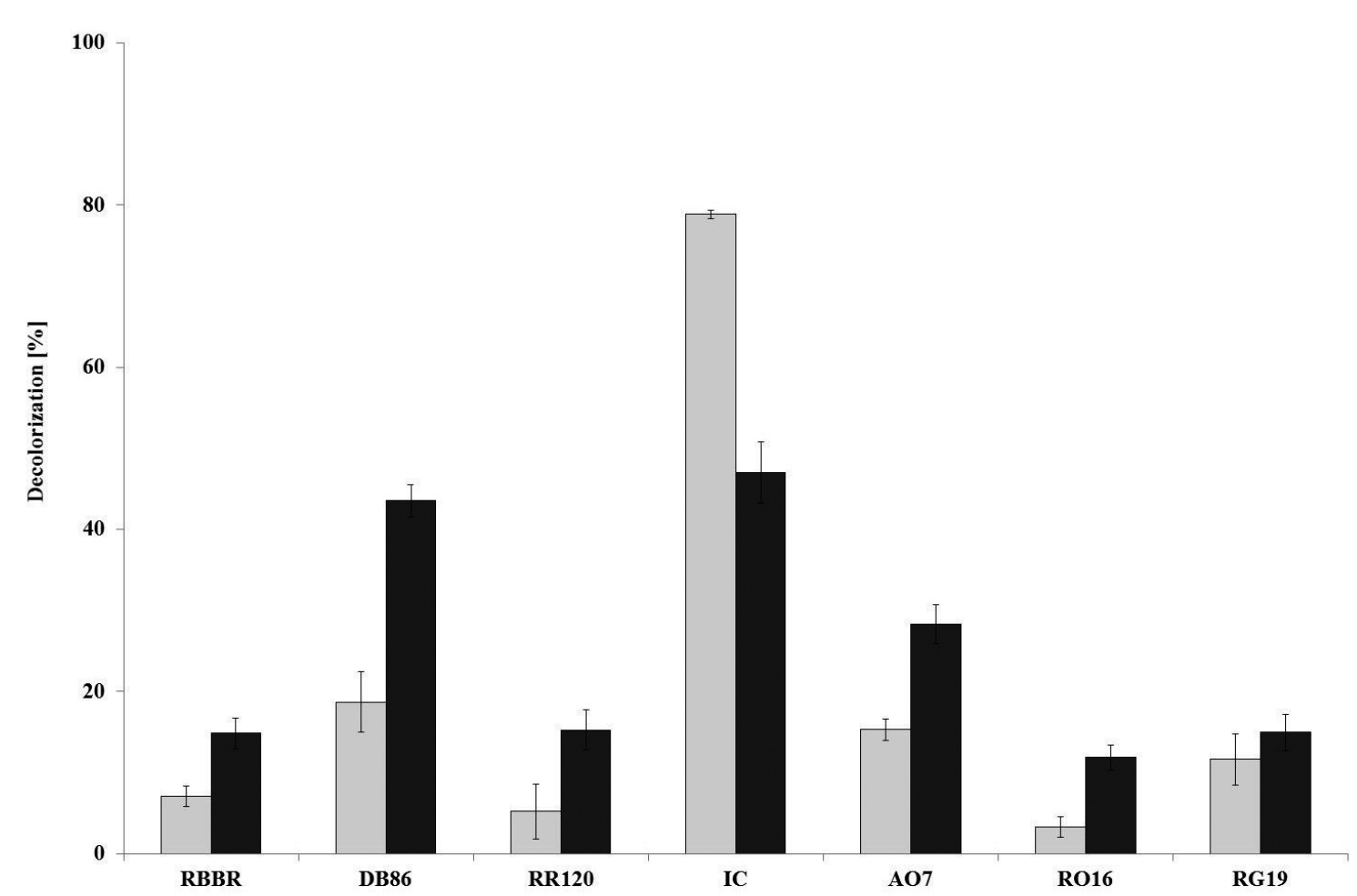

Figure 4. Decolorization of various dyes by crude LMCOs of $M$. roridum. Activity of MCOs at $1 \mathrm{U} / \mathrm{mL}$; dye at 10 (grey) or 50 (black) $\mathrm{mg} / \mathrm{L}$. 
A

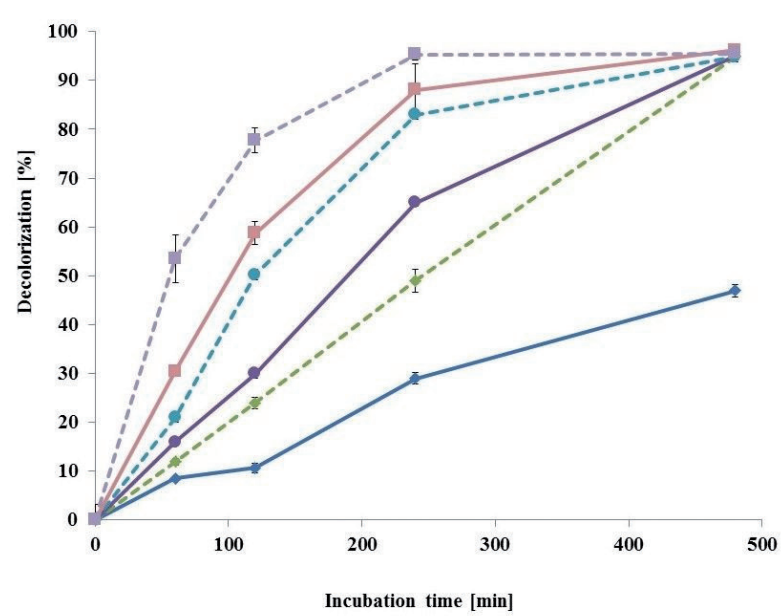

B

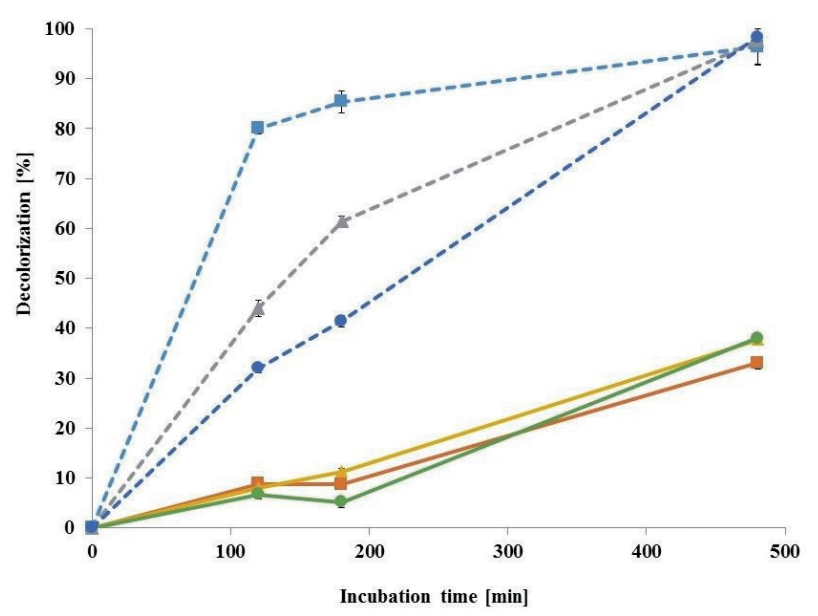

Figure 5. Indiago carmine decolorization by M. roridum LMCOs. A) Fffect of vanillin concentration on dye decolorization (50 mg/L);

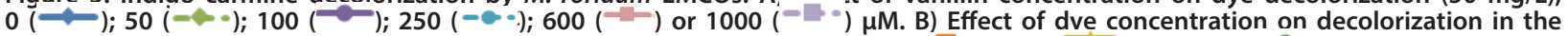
presence of vanillin (1900 $\mu \mathrm{M})$ or without the mediator. Without vanillin: $50(-)$ ); $100(-)$ and 200 (

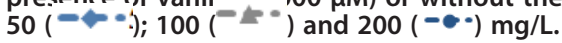

Dye decolorization in the enzyme-mediator system

The use of vanillin allowed obtaining an Indigo carmine decolorization reaching above $65 \%$ within 3 hours of incubation. At the same time, removal of the dye from the solution without any mediators, reached only $30 \%$. Decolorization of Indigo carmine was strongly affected by the vanillin concentration (Fig. 5A). Higher concentrations of the mediator provided higher decolorization percentages. The maximum decolorization (95\%) of Indigo carmine was reached after 3 hour incubation with $1000 \mu \mathrm{M}$ vanillin. After 24 hours of incubation, and in the absence of the mediator, the dye was decolorized in only $47 \%$, whereas in the presence of all tested vanillin concentrations the dye was decolorized almost completely. Moreover, the use of vanillin as a mediator allowed an increase in the concentration of the dye (Fig. 5B). In the presence of $1000 \mu \mathrm{M}$ vanillin, as much as $200 \mathrm{mg} / \mathrm{L}$ Indigo carmine could be decolorized up to $98 \%$ within 8 hours.

Dye decolorization in the presence of metals, chloride, surfactants and organic solvents

The influence of four different surfactants (two ionic and two non-ionic) on Indigo carmine elimination by crude $M$. roridum LMCOs was studied. Non-ionic surfactants, such as Triton X-100 and Tween 80, did not affect the Indigo carmine elimination (Fig. 6). The level of decolorization after 3 hours of incubation was similar to that determined for controls (98\%) and achieved at 93 and $97 \%$, respectively. In the presence of cationic surfactant (SDS) and anionic CTAB, an inhibitory effect was seen. Indigo carmine removal was not influenced by any of the tested inorganic compounds. Indigo carmine decolorization by crude LMCOs from $M$. roridum in the presence of $\mathrm{NaCl}$ was not significantly affected. The enzyme was active and decolorized the dye in the presence of ethyl and methyl alcohol.

Dye decolorizing protein identification

Native-PAGE and an in situ staining of the activity using ABTS showed two protein bands characterized

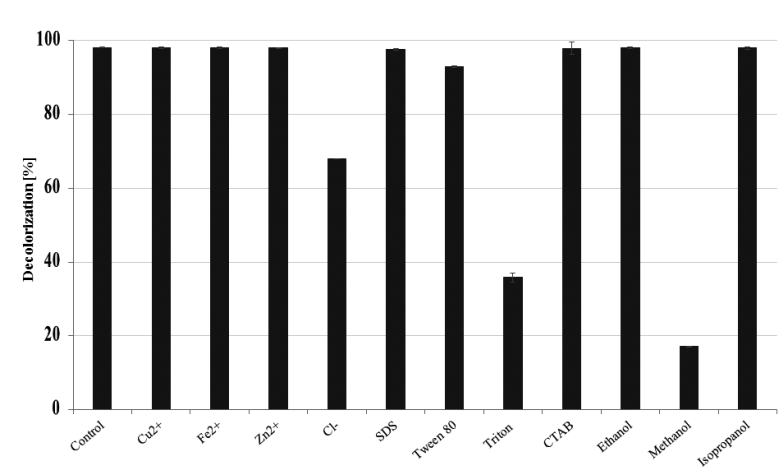

Figure 6. Decolorization of Indigo carmine by $M$. roridum LMCOs in the presence of different auxiliary compounds. Activity of MCOs at $1 \mathrm{U} / \mathrm{L}$; dye $200 \mathrm{mg} / \mathrm{L}$; vanillin $1000 \mu \mathrm{M}$.

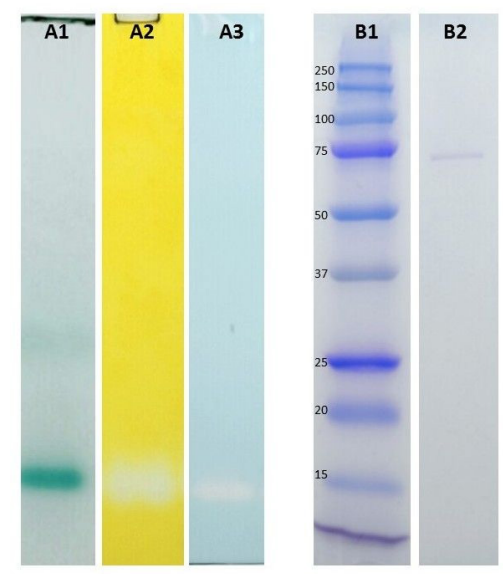

Figure 7. Electrophoretic inspection of $M$. roridum extracellular proteins.

(A) Native-PAGE gel stained with: A1) ABTS; A2) bilirubin or A3) Indigo carmine with $1000 \mu \mathrm{M}$ of vanillin. (B) SDS-PAGE of: B1) molecular mass marker or B2) protein extracted from a band showing a decolorized zone. 
by activity towards ABTS. However, only one of them had the ability to oxidize bilirubin, as well as decolorize Indigo carmine (Fig. 7A). This protein was extracted and used for molecular weight inspection by SDS-PAGE (Fig. 7B). SDS-PAGE showed the presence of the protein with a molecular weight of approximately $70 \mathrm{kDa}$, which corresponds to results obtained for LMCO2 identified earlier (as shown on Fig 3).

\section{DISCUSSION}

Most of the fungal extracellular MCOs, including laccases, are constitutively produced in small amounts. However, an increased production of these enzymes due to changes in operational parameters and media optimization has been already reported (Piscitelli et al., 2011; Gupta et al., 2015). Our preliminary shake flask cultures, using a commercial Czapek-Dox medium, showed the ability of $M$. roridum IM 6482 to produce a slight amount $(0.74$ $\mathrm{U} / \mathrm{L}$ ) of the enzyme with laccase activity (Jasińska et al., 2012). Hence, it was suggested to modify the culture conditions to increase production of the laccase-like enzymes. The carbon and nitrogen sources, as well as inducer supplementation, were tested to improve the enzyme production. The production of the laccase-like enzyme reached its maximum level when $7.50 \mathrm{~g} / \mathrm{L}$ of glucose and 3.00 $\mathrm{g} / \mathrm{L}$ of yeast extract were used. At higher glucose concentrations, the enzyme production decreased. According to Galhaup and Haltrich (2001), when using glucose as a carbon source, Trametes pubescens laccase formation starts only when this substrate is almost completely depleted from the medium. Low glucose content in the medium could be beneficial by preventing catabolic repression, which is often observed for extracellular enzyme production (Galhaup et al., 2002). Both, the nature and concentration of the nitrogen source used for cultivation, are reported to be of considerable importance for laccase-like enzyme production (Majeau et al., 2010). However, changes in the laccase activity in response to the nitrogen concentration are a controversial issue because examples of increased activity have been described under limiting and non-limiting conditions (Piscitelli et al., 2011). According to Sivakumar and coworkers (2010), inorganic nitrogen sources lead to low levels of laccase with sufficient biomass production, while organic nitrogen sources yield high laccase levels with good fungal growth. In our study, the laccase-like enzyme production in the presence of yeast extract was similar to that achieved in a medium containing $\mathrm{NaNO}_{3}$, but the enzyme was synthesized faster, and the highest activity was achieved within 48 hours of cultivation instead of 144 hours. Hou and coworkers (2004) also demonstrated peptone and yeast extract to be the most suitable nitrogen sources for the laccase production by Pleurotus ostreatus strain 32, in comparison with urea, ammonium sulfate, and ammonium tartrate. Similarly, replacement of ammonium sulfate by yeast extract led to a 5.7 -fold increase in P. ostreatus Pl 22 Em laccase activity (Karp et al., 2015).

Because obtaining MCOs by recombinant expression of genes is relatively expensive for the demands of industrial applications, the development of environmentally-friendly and cost-effective methods for the production of laccase with high efficiency is a top priority. MCOs are coppercontaining proteins, so copper supplementation as a micronutrient in the culture medium has been reported to enhance the enzyme production in many fungi (Chen et al., 2003). Different studies have shown that copper-induced laccase production is regulated by gene expression induction or through translational or post-translational reg- ulation. Copper has been reported to be a strong inducer of MCOs produced by the species of Trametes versicolor, T. birsuta, T. trogii, and Aspergillus flavus (Gomaa et al., 2015; Vasina et al., 2015; Campos et al., 2016). In our study, addition of copper ions (at $1 \mathrm{mM}$ ) to the growth medium enhanced laccase production by more than 7-times. Copper ions can not only induce laccase production by the expression of laccase genes in P. ostreatus CCBAS-447, but they can also positively influence the activity and stability of the enzyme (Baldrian \& Gabriel, 2002). Palmieri and coworkers (2001) described a significant suppression of an extracellular protease in the presence of $1 \mathrm{mM} \mathrm{Cu}$. This might explain a higher positive effect of $\mathrm{Cu}$ on the laccase stability. Also, phenolic and aromatic compounds, structurally related to lignin or lignin derivatives, are routinely added to fungal cultures to increase the laccase production. M. roridum IM 6482 is a plant pathogen, so the laccase induction by phenolic substances may represent a response developed by the fungi against the phenolic intermediates of lignin degradation (Piscitelli et al., 2011). A laccase stimulatory effect of guaiacol has been found in Phlebia spp. and P. ostreatus (Hou et al., 2004). According to Piscitelli and coworkers (2011), induction of the aromatic compounds has been found to occur at the transcriptional level, differing not only among the various fungi but also among the different isoenzymes of the same organism. The $M$. roridum laccase-like enzymes were significantly induced by guaiacol $(20 \mathrm{mM})$, which enhanced the enzyme production by up to two-folds. Significant laccase induction for the unidentified fungal strain MTTC 5159 has been achieved using a medium containing one of the three synthetic dyes - brilliant green, blue aniline or Congo red (D'Souza et al., 2006). But in our study, suppression of laccase synthesis was observed in the presence of dyes at the initial concentration of $10 \mathrm{mg} / \mathrm{L}$. This could have been caused by high toxicity of these compounds.

To identify the laccase-like enzymes of $M$. roridum, the extracellular proteins precipitated using ammonium sulfate were purified by ion-exchange chromatography. Two fractions with laccase activity, annotated as LMCO1 and LMCO2, were obtained and had molecular masses of 46.7 and $66.3 \mathrm{kDa}$, respectively. The protein bands were ingel digested and a MALDI-TOF/TOF analysis was then performed. However, the purified proteins could not be clearly identified due the fact that characteristic peptide sequences were obtained for several enzymes, such as MCOs from Macrophomina phaseolina MS6, and bilirubin oxidase from Myrothecium verrucaria and Magnaporthe oryzae. Recently, several novel enzymes with properties typical for laccase (e.g., structure and substrate specificity) could not be classified as laccases due to their low sequence homology and differences in the amino acid sequence composition of the copper binding site (Beloqui et al., 2006). Many problems are often caused during the process of enzyme identification whose amino acid sequences are not known or which have not been deposited in the databases. Moreover, the broad substrate specificity of MCOs and overlapping oxidation activity hamper classification. Reiss et al. (2013) identified, characterized and classified a new CotAtype enzyme from Bacillus pumilus as a laccase. Durand et al. (2012) also studied the B. pumilus enzyme and found a 98\% sequence identity to this CotA-type enzyme but assigned it as a bilirubin oxidase. Similarly, the Bacillus subtilis endospore component CotA, which has a relatively high (19.7 to $22.4 \%$ ) amino acid sequence identity with MCOs and the crystal structure of a protein, was identified as a laccase (Martins et al., 2002). Notably, when the $\cot A$ gene was expressed in Escherichia coli, it was found that in addition to the previously identified laccase activity, the 
enzyme also displayed a strong bilirubin oxidase activity (Sakasegawa et al., 2006).

However, in our study the Delta-BLAST analysis showed that LMCO1, as well as LMCO2, belong to the cupredoxin superfamily. Also, histidine-rich amino acid sequences typical for MCOs were found. Sakurai and Kataoka (2007) stated that it is very difficult to exactly define what a "true" laccase is and proposed to introduce the term "laccase-like MCOs" (LMCOs). Thus, we decided that use of this term is more appropriate in the case of $M$. roridum enzymes. Recently, enzymes with a laccase activity isolated from different Myrothecium verrucaria strains have been identified as bands with a molecular mass of 62 or $66 \mathrm{kDa}$ (Sulistyaningdyah et al., 2004; Zhao et al., 2012). However, in this study, LMCOs from the species of $M$. roridum were characterized for the first time.

Microbial laccases are potential tools for biological strategies in the elimination of synthetic dyes $\mathrm{Xu}$ et al., 2016). Approaches applying crude enzymes can greatly reduce the cost of such process operation. Decolorization of the triphenylmethane dye, i.e. Malachite green, by $M$. roridum has been previously described (Jasińska et al., 2012, 2015). The dye elimination was due to the action of a laccase-like enzyme and low molecular weight factors. In our study, crude enzymes of $M$. roridum were used for the removal of different dyes (belonging to an indigoid, anthraquinone, azo and phthalocyanine class) from an aqueous solution. The dyes tested in this study were decolorized to varying degrees and the highest decolorization was obtained for Indigo carmine. Indigo colorants that are durable upon exposure to heating, sunlight and extreme $\mathrm{pH}$, are largely used to dye the denim fabric. Indigo carmine is considered as a highly toxic indigoid class of dye and contact with this substance can cause skin and eye irritation in humans. It can also cause permanent injury to the cornea and conjunctiva (Dogdu \& Yalcuk, 2016). Therefore, very large amounts of indigo dye-containing wastewater, especially the textile effluent, must be treated before being discharged into the environment. Recently, several other authors have also reported decolorization of Indigo carmine. However, these studies have been mainly concerned with physicochemical methods of dye elimination, as well as the use of bacterial or basidiomycetous laccases (Ahmed et al., 2017; Paz et al., 2017).

Some dyes are not suitable substrates for the laccasemediated degradation and their degradation depends on the presence of chemical compounds called mediators. Thus, to accelerate the dye elimination, a natural mediator - vanillin was used. $\mathrm{Li}$ and coworkers (2014) studied mediator assisted decolorization of Indigo carmine by crude laccase derived from Trametes sp. SYBC-L4. After 36 hours of incubation with a synthetic mediator (hydroxybenzotriazole (HBT)), 99\% of Indigo carmine (100 $\mathrm{mg} / \mathrm{L})$ was decolorized. Vanillin has been reported as a suitable laccase mediator in the decolorization of dyes and pesticide degradation (Camarero et al., 2005; Jin et al., 2016). The high costs of some synthetic mediators and their potential toxic and harmful character mean that the laccase systems mediated by natural compounds could be an eco-friendly solution. The decolorization of Indigo carmine was strongly affected by the vanillin concentration. Moreover, the use of this mediator allowed an increase in the concentration of the dye. In the presence of $1000 \mu \mathrm{M}$ vanillin, as much as $200 \mathrm{mg} / \mathrm{L}$ of Indigo carmine were completely decolorized within 8 hours. Similar results were obtained by Lu and coworkers (2016) using a crude laccase from Ganoderma sp. En3. However, that enzyme decolorized $90 \%$ of Indigo carmine at a concentration of $200 \mathrm{mg} / \mathrm{L}$ within 30 hours.
Depending on the dyeing process, many chemicals, e.g. metals, salts, organic solvents and surfactants, may be added to improve dye adsorption onto fibers (Sarayu \& Sandhya, 2012). Thus, improved tolerance to these compounds is an enviable quality for laccase application in organic chemistry. In the present study, Indigo carmine was efficiently removed from a solution containing metals, surfactants and organic solvents. The tested non-ionic surfactants and inorganic compounds (e.g. $\mathrm{NaCl}$, metal ions) did not affect the Indigo carmine elimination. On the contrary, $\mathrm{NaCl}$ and heavy metal ions significantly inhibited the efficiency of dye decolorization by laccases from Ganoderma lucidum, Trametes sp. and Trametes trogii (Manel et al., 2009; Zilly et al., 2011), even at low concentrations. The LMCOs produced by $M$. roridum were also active and decolorized Indigo carmine in the presence of the ethyl and methyl alcohol. Only the cationic surfactant (SDS) and anionic CTAB demonstrated an inhibitory effect, which may be due to the inhibition of the enzyme activity. These results revealed that crude laccase from $M$. roridum is active and efficiently decolorizes dyes, even in the presence of chemicals recognized as enzyme inhibitors which are commonly found in the textile wastewater (Zilly et al., 2011).

Because in our study a crude extract of $M$. roridum extracellular proteins has been used for decolorization, in the next stage it was necessary to verify whether the enzymes responsible for the decolorization of dyes are actually LMCOs. For this purpose Native-PAGE and an in situ staining of the activity using ABTS, bilirubin and Indigo carmine were conducted. Only one protein with ABTS and bilirubin oxidizing activity demonstrated the Indigo carmine in-gel decolorization. Extraction of the protein from this decolorized band and SDS-PAGE confirmed that only the enzyme annotated earlier as LMCO2 was responsible for the dye removal. Protein extraction from decolorized bands after dye staining was used for dye decolorizing protein identification for the first time. So far, in-gel assessment of the activity and decolorizing potential of only some laccase had been performed (Murugesan et al., 2007; Iracheta-Cárdenas et al., 2016).

In conclusion, production of two $M$. roridum LMCOs was demonstrated. Proteins annotated as LMCO1 and LMCO2 were identified by mass spectrometry and had molecular masses of about 44.6 and $66.3 \mathrm{kDa}$, respectively. Production of these enzymes was enhanced by almost 10 -folds and their decolorizing potential was characterized for the first time. $M$. roridum MCOs eliminated Indigo carmine within 4 hours, especially in the presence of vanillin, and even in the presence of metal ions, chloride, surfactants and organic solvents. A novel method for the identification of the enzymes used in this study allowed to point to LMCO2 as the major dye decolorizing enzyme.

\section{Acknowledgements}

This work is a result of project No. UMO 2013/11/D/NZ9/02776 financed by the National Science Center of Poland.

\section{REFERENCES}

Ahmed MA, Brick AA, Mohamed AA (2017) An efficient adsorption of indigo carmine dye from aqueous solution on mesoporous $\mathrm{Mg}$ / Fe layered double hydroxide nanoparticles prepared by controlled sol-gel route. Chemosphere 174: 280-288

Baldrian P, Gabriel J (2002) Copper and cadmium increase laccase activity in Pleurotus ostreatus. FEMS Microbiol Lett 206: 69-74. doi: 10.1016/S0378-1097(01)00519-5

Beloqui A, Pita M, Polaina J, Martínez-Arias A, Golyshina OV, Zumárraga $M$, Yakimov MM, García-Arellano $H$, Alcalde $M$, Fernández VM, Elborough K, Andreu JM, Ballesteros A, Plou FJ, Timmis 
KN, Ferrer M, Golyshin PN (2006) Novel polyphenol oxidase mined from a metagenome expression library of bovine rumen: biochemical properties, structural analysis, and phylogenetic relationships. J Biol Chem 281: 22933-22942. doi: 10.1074/jbc.M600577200

Camarero S, Ibarra D, Martínez MJ, Martínez AT (2005) Lignin-derived compounds as efficient laccase mediators for decolorization of different types of recalcitrant dyes. Appl Environ Microbiol 71: 17751784. doi: 10.1128/AEM.71.4.1775-1784.2005

Campos PA, Levin LN, Wirth SA (2016) Heterologous production, characterization and dye decolorization ability of a novel thermostable laccase isoenzyme from Trametes trogii BAFC 463. Process Biochem 51: 895-903. https://doi.org/10.1016/j.procbio.2016.03.015

Chen S, Ma D, Ge W, Buswell JA (2003) Induction of laccase activity in the edible straw mushroom, Volvariella volvacea. FEMS Microbiol Lett 218: 143-148. doi: 10.1016/S0378-1097(02)01131-X

Desai S, Nityanand C (2011) Microbial laccases and their applications: a review. Asian J Biotech 3: 98-124. doi: 10.3923/ajbkr.2011.98.124

Dogdu G, Yalcuk A (2016) Indigo dyeing wastewater treatment by eco-friendly constructed wetlands using different bedding media. Desal Water Treat 57: 15007-15019. https://doi.org/10.1080/19443 994.2015.1070290

D’Souza DT, Tiwari R, Sah AK, Raghukumar C (2006) Enhanced production of laccase by a marine fungus during treatment of colored effluents and synthetic dyes. Ensyme Microb Tech 38: 504-511. https://doi.org/10.1016/j.enzmictec.2005.07.005

Durand F, Kjaergaard CH, Suraniti E, Gounel S, Hadt RG, Solomon EI, Mano N (2012) Bilirubin oxidase from Bacillus pumilus: a promising enzyme for the elaboration of efficient cathodes in biofuel cells. Biosens Bioelectron 35: 140-146. doi: 10.1016/j.bios.2012.02.033

Eggert C, Temp U, Dean JFD, Eriksson KEL (1996) A fungal metabolite mediates degradation of non-phenolic lignin structures and synthetic lignin by laccase. FEBS Lett 391: 144-148. https://doi. org/10.1016/0014-5793(96)00719-3

Galhaup C, Goller S, Peterbauer CK, Strauss J, Haltrich D (2002) Characterization of the major laccase isoenzyme from Trametes $p u-$ bescens and regulation of its synthesis by metal ions. Microbiology 148: 2159-2169. doi: 10.1099/00221287-148-7-2159

Galhaup C, Haltrich D (2001) Enhanced formation of laccase activity by the white-rot fungus Trametes pubescens in the presence of copper. Appl Microbiol Biotechnol 56: 225-232. doi: 10.1007/s002530100636

Gomaa OM, Momtaz OA (2015) Copper induction and differential expression of laccase in Aspergillus flavus. Braz J Microbiol 46: 285-292. doi: 10.1590/S1517-838246120120118

Gupta VK, Khamparia S, Tyagi I, Jaspal D, Malviya A (2015) Decolorization of Mixture of Dyes: A Critical Review. Global I Environ Sci Manage 1: 71-94. doi: 10.7508/gjesm.2015.01.007

Hoegger PJ, Kilaru S, James TY, Thacker JR, Kües U (2006) Phylogenetic comparison and classification of laccase and related multicopper oxidase protein sequences. FEBS I 273: 2308-2326. doi: $10.1111 /$ j.1742-4658.2006.05247

Hou H, Zhou J, Wang J, Du C, Yan B (2004) Enhancement of laccase production by Pleurotus ostreatus and its use for the decolorization of anthraquinone dye. Process Biochem 39: 1415-1419. https://doi. org/10.1016/S0032-9592(03)00267-X

Iracheta-Cárdena, MM, Rocha-Peña MA, Galán-Wong LJ, ArévaloNiño K, Tovar-Herrera OE (2016) A Pycnoporus sanguineus laccase for denim bleaching and its comparison with an enzymatic commercial formulation. J Environ Manage 177: 93-100. doi: 10.1016/j. jenvman.2016.04.008

Jasińska A, Bernat P, Paraszkiewicz K (2013) Malachite Green removal from aqueous solution using the system rapeseed press cake and fungus Myrothecium roridum. Desalin Water Treat 51: 7663-7671. https://doi.org/10.1080/19443994.2013.779939

Jasińska A, Góralczyk A, Długoński J (2016) Dye decolorization and degradation by microorganisms. In: Microbial Biodegradation: From Omics to Function and Application. Długoński J ed, pp.119-141, Caister Academic Press, Norfolk. https://doi.org/10.21775/9781910190456.08

Jasińska A, Paraszkiewicz K, Sip A, Długoński, J (2015) Malachite Green decolorization by the filamentous fungus Myrothecium roridum- Mechanistic study and process optimization. Biores Technol 194: 43-48. doi: 10.1016/j.biortech.2015.07.008

Jasińska A, Różalska S, Bernat P, Paraszkiewicz K, Długoński J (2012) Malachite Green decolorization by non-basidiomycete filamentous fungi of Penicillium pinophilum and Myrothecium roridum. Int Biodeter Biodegr 73: 33-40. https://doi.org/10.1016/j.ibiod.2012.06.025

Jin X, Yu X, Zhu G, Zheng Z, Feng F, Zhang Z (2016) Conditions Optimizing and Application of Laccase-mediator System (LMS) for the Laccase-catalyzed Pesticide Degradation. Scientific Reports Article number: 35787 . doi: 10.1038/srep35787

Karp SG, Faraco V, Amore A, Letti LAJ, Soccol VT, Soccol CR (2015) Statistical optimization of laccase production and delignification of sugarcane bagasse by Pleurotus ostreatus in solid-state fermentation. BioMed Res Int doi: 10.1155/2015/181204

Levin L, Herrmann C, Papinutti VL (2008) Optimization of lignocellulolytic enzyme production by the white-rot fungus Trametes trogii in solid-state fermentation using response surface methodology. Biochem Eng J 39: 207-214. doi: 10.1016/j.bej.2007.09.004

Li HX, Zhang RJ, Tang L, Zhang JH, Mao ZG (2014) In vivo and in vitro decolorization of synthetic dyes by laccase from solid state fermentation with Trametes sp. SYBC-L4. Bioprocess Biosyst Eng 37: 2597-2605. doi: 10.1007/s00449-014-1237-y

Lu R, Ma L, He F, Yu D, Fan R, Zhang Y, Long Z, Zhang X, Yang $\mathrm{Y}$ (2016) White-rot fungus Ganoderma sp.En3 had a strong ability to decolorize and tolerate the anthraquinone, indigo and triphenylmethane dye with high concentrations. Bioprocess Biosyst Eng 39: 381-390. doi: 10.1007/s00449-015-1521-5

Majeau JA, Brar SK, Tyagi RD (2010) Laccase for removal of recalcitrant and emerging pollutants. Biores Technol 101: 2331-2350. doi: 10.1016/j.biortech.2009.10.087

Manel MK, Hela ZM, Lassaad B, Steve W, Tahar M (2009) Malachite Green decolourization and detoxification by the laccase from a newly isolated strain of Trametes sp. Int Biodeterior Biodeg 63: 600-606. https://doi.org/10.1016/j.ibiod.2009.04.003

Martins LO, Soares CM, Pereira MM, Teixeira M, Costa T, Jones GH, Henriques AO (2002) Molecular and biochemical characterization of a highly stable bacterial laccase that occurs as a structural component of the Bacillus subtilis endospore coat. J Biol Chem 277: 18849-18859. doi: 10.1074/jbc. M200827200

Murugesan K, Nam I-H, Kim Y-M, Chang Y-S (2007) Decolorization of reactive dyes by a thermostable laccase produced by Ganoderma Iucidum in solid state culture. Enz Microb Technol 40: 1662-1672. https://doi.org/10.1016/j.enzmictec.2006.08.028

Palmieri G, Bianco C, Cennamo G, Giardina P, Marino G, Monti M, Sannia G (2001) Purification characterization and functional role of a novel extracellular protease from Pleurotus ostreatus. Appl Environ Microbiol 67: 2754-2759. doi: 10.1128/AEM.67.6.2754-2759.2001

Paz A, Carballo J, Pérez MJ, Domínguez JM (2017) Biological treatment of model dyes and textile wastewaters. Chemosphere 181: 168177. doi: 10.1016/j.chemosphere.2017.04.046

Piscitelli A, Giardina P, Lettera V, Pezzella C, Sannia G, Faraco V (2011) Induction and transcriptional regulation of laccases in fungi. Curr Genomics 12: 104-112. doi: 10.2174/138920211795564331

Reiss R, Ihssen J, Richter M, Eichhorn E, Schilling B, Thöny-Meyer L (2013) Laccase versus laccase-like multi-copper oxidase: A comparative study of similar enzymes with diverse substrate spectra. PLOS ONE 8: e65633. doi:10.1371/journal.pone.0065633

Sakasegawa SI, Ishikawa H, Imamura S, Sakuraba H, Goda S, Ohshima T (2006) Bilirubin oxidase activity of Bacillus subtilis CotA. Appl Environ Microbiol 72: 972-975. doi: 10.1128/AEM.72.1.972-975.2006

Sakurai T, Kataoka K (2007) Basic and applied features of multicopper oxidases, CueO, bilirubin oxidase, and laccase. Chem Rec 7: 220-229. doi: $10.1002 /$ tcr.20125

Sarayu K, Sandhya S (2012) Current Technologies for Biological Treatment of Textile Wastewater-A Review. Appl Biochem Biotechnol 167: 645-661. doi: 10.1007/s12010-012-9716-6

Sivakumar R, Rajendran R, Balakumar C, Tamilvendan M (2010) Isolation, screening and optimization of production medium for thermostable laccase production from Ganoderma sp. Int I Environ Sci Tech 2: 7133-7141. doi: 10.20546/ijcmas.2017.604.289

Soboń A, Szewczyk R, Długoński J (2016) Tributyltin (TBT) biodegradation induces oxidative stress of Cunninghamella echinulate. Int Biodeterior Biodegr 107: 92-101. https://doi.org/10.1016/j.ibiod.2015.11.013

Sulistyaningdyah WT, Ogawa J, Tanaka H, Maeda C, Shimizu S (2004) Characterization of alkaliphilic laccase activity in the culture supernatant of Myrothecium verrucaria 24G-4 in comparison with bilirubin oxidase. FEMS Microbiol Lett 230: 209-214. https://doi. org/10.1016/S0378-1097(03)00892-9

Szewczyk R, Soboń A, Słaba M, Długoński J (2015) Mechanism study of alachlor biodegradation by Paecilomyces marquandii with proteomic and metabolomic methods. J Hazard Mater 291: 52-64. doi: 10.1016/j.jhazmat.2015.02.063

Vasina DV, Mustafaev ON, Moiseenko KV, Sadovskaya NS, Glazunova OA, Tyurin AA, Fedorova TV, Pavlov AR, Tyazhelova TV, Goldenkova-Pavlova IV, Koroleva OV (2015) The Trametes hirsute 072 laccase multigene family: Genes identification and transcriptional analysis under copper ions induction. Biochimie 116: 154-164. doi: 10.1016/j.biochi.2015.07.015

Xu Y, Lu Y, Zhang R, Wang H, Liu Q (2016) Characterization of a novel laccase purified from the fungus Hobenbuehelia serotina and its decolourisation of dyes. Acta Biochim Pol 63: 273-279. doi: 10.18388/abp.2015_1091

Zhao D, Zhang X, Cui D, Zhao M (2012) Characterisation of a novel white laccase from the Deuteromycete fungus Myrothecium verrucaria NF-05 and its decolourisation of dyes. PLoS One doi: 10.1371/journal.pone.0038817.

Zilly A, Coelho-Moreira JD, Bracht A, de Souza CGM, Carvajal AE, Koehnlein EA, Peralta RM (2011) Influence of $\mathrm{NaCl}$ and $\mathrm{Na}_{2} \mathrm{SO}_{4}$ on the kinetics and dye decolorization ability of crude laccase from Ganoderma lucidum. Int Biodeterior Biodegr 65: 340-344. https://doi. org/10.1016/j.ibiod.2010.12.007 